\title{
Automatic Zinc Sampler Saves Handling Time
}

\author{
by Fred J. Meek
}

\section{$\mathrm{C}$} ONVERSION from industrial railway and hand handling of slab zinc to fork truck handling called for an improved method of sampling to replace the old drill press method. American Zinc Co. of Illinois' solution to the problem is an automatic sampler capable of taking two simultaneously drilled samples from a 44 plate bundle, while positioned under the drill guides by the fork truck. The drilling is done as the bundle is raised off the metal scales. The operation of the drills is by a suspended

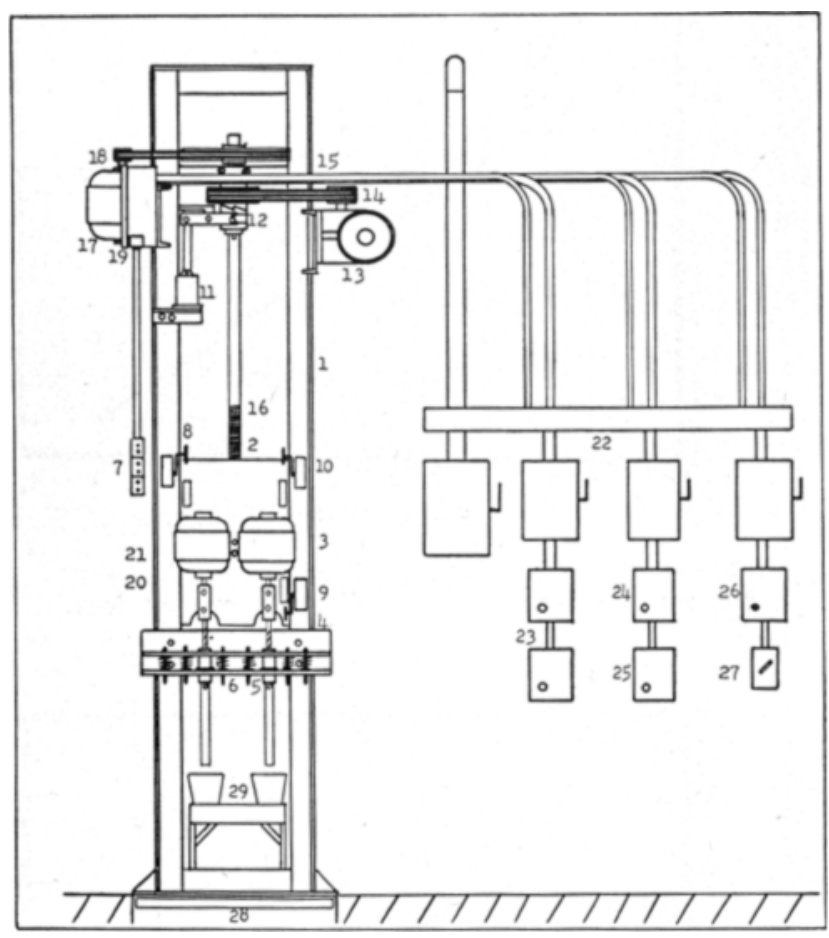

Fig. 2-The sampler consists of: 1-Frame and slide plate guides, 2-slide plate, 3-drill motors, 4-drills, 5-drill guides and sample chutes, 6-holding pins and springs, 7start-stop buttons, 8-up-motor limit switch, 9-down-motor and clutch limit switch, 10-drill control switch, 11-clutch selenoid, 12-down-clutch, quill, and shifter, 13-down-gear motor, 14-drive, 15-anti-friction bearing and support, 16thread bar, 17-up-motor, 18-drive, 19-test terminals junction box, 20-anti-friction thrust bearing, rear, 21thread bar nut on slide plate, rear, 22-fused disconnect switches, 23, 24, 25, 26-magnetic starters for drill motors, down-gear magnetic motor, clutch selenoid, and up-motor, 27-inching switch for drill removal, 28-scale platform, 29-sample pans.
Fig. 1-Conversion to use of the fork truck and automatic spelter sampler has resulted in an overall saving of about $60 \mathrm{pct}$ in handling metal from the furnaces to the railroad cars.

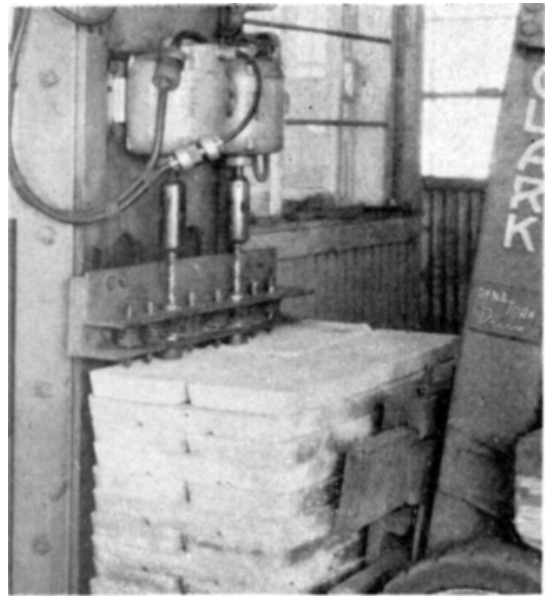

push button, touched by the fork truck operator by moving his left hand a few inches from the steering wheel. The whole operation is a natural action. It adds little to the job of transportation and weighing - except for positioning, pressing the starting buttons, and waiting for the completion of the automatic drilling cycle.

Fig. 1 is the twin drill unit constructed in American Zinc shops after considerable pilot test work. Conventional parts are used except for the drill guides and chip collecting cups with chutes, as illustrated by the sectional drawing in Fig. 2. The apparatus is principally a simple motor operated raising and lowering device. Much experimenting was required to arrive at the production of chips that would flow down the delivery chutes. To date, only the use of standard $1 / 2$ in. high speed twist drills driven at $1760 \mathrm{rpm}$ with a feed of 0.0017 in. per revolution seems to produce chips instead of spiral curls in drilling spelter either hot or cold. Stainless steel guide bushings have given the best nongalling, nonseizing service for this use. The guide bushings must be without lubrication to avoid contamination.

The drilling operation, while set in motion by a push button, is further controlled as to feed, drill rotation, stopping, withdrawal, stopping of withdrawal and stopping of drill rotation by standard limit switches and a series of magnetic starter switches interlocked or actuating one another. A slow down-feed is achieved by a motor reducer drive which is de-clutched on the up-run. A fast withdrawal is attained by a direct $\mathrm{v}$-belted motor which is never de-clutched, but runs slowly backward on the down-run. To steady the plate bundle and permit drilling on an uneven pile, the drill guides and a number of pointed steadying pins are pressed downward against the raised load by heavily compressed springs. A manual switch on the control panel is used for inching up enough for new drill insertion.

The combined conversion to transportation by fork truck and the use of automatic sampling has reduced the crew size from eight men to two men and has eliminated an industrial locomotive, rolling stock, and some other equipment. Two fork trucks, plate stacking racks, and the automatic sampler have been added. The result is an overall saving of about 60 pct in handling metal from the furnaces to railroad cars.

FRED J. MEEK is Plant Engineer of American Zinc Co. of Illinois, Fairmont plant, East St. Louis, III. 